\title{
Evaluating and Guiding the Development of Sustainable Biorenewable Chemicals with Feasible Space Analysis
}

Sampath Gunukula ${ }^{\mathrm{a}}$, Robert Anex ${ }^{\mathrm{a}^{*}}$

\begin{abstract}
The economic and environmental performance of a biorenewable chemical process is analyzed by defining its cost, energy, and greenhouse gas feasible design spaces in terms of process parameters. Delimiting the feasible space of a process allows developers to set development targets and quantify performance trade-offs among unit processes. Feasible space analysis is demonstrated for the biocatalytic synthesis of C10 saturated fatty acid from glucose. Capric acid yield from glucose of $\geq 0.25 \mathrm{~g} \mathrm{~g}^{-1}$, titer of $\geq 40 \mathrm{~g} \mathrm{l}^{-1}$, and volumetric productivity of 2 $\mathrm{g}^{-1} \mathrm{~h}^{-1}$ are found to result in cost, greenhouse gas emissions, and energy consumption as good as or better than the conventional process for production of fatty acids from coconut oil.
\end{abstract}

Key words: Biocatalysis, Biomass conversion, Process development, Feasible space, Fatty acid, Sustainability 


\section{Introduction}

There is growing interest in biorenewable chemicals because of their perceived economic and environmental benefits [1]. It is expected that production from renewable, plant-derived sugars should, in the long-run, allow a low cost of production relative to conventional petrochemicals. Environmental benefits are also expected through the use of biorenewable feedstocks, particularly in terms of carbon footprint. Unfortunately, none of these benefits are certain and recent biorenewable chemical investments have included some high-profile disappointments [2]. To avoid such disappointments, the economic potential and environmental sustainability of a new biorenewable chemical production process should be determined before large irreversible investments are made in process development and scale-up to production scale.

The techno-economic analysis (TEA) and life cycle assessment (LCA) methods are often used to assess the economic and environmental performances of new chemical processes [3,4]. One process configuration or a single combination of process parameters (yield, selectivity, etc.) is usually evaluated when assessing the potential of a new chemical process [4]. If such analyses indicate that a process is not economically viable and environmentally sustainable, then further development may be stopped. The economic and environmental feasibility of a new chemical process, however, still may be achieved by further improvement of the process. It is, therefore, necessary to assess the performance of a new chemical process over a range of combinations of process parameters in order to determine the combinations that would be economically and environmentally feasible. In this manner, one can avoid eliminating processes that are currently unviable but could potentially be made viable. Knowledge of which combinations of process parameters would make the process viable can guide the efforts of process development teams, 
allowing them to focus on improving those process parameters that, on the basis of the current stage of technology, are not in the feasible range.

A new biomass conversion technology (biological, chemical, and thermo-chemical) has to pass through multiple stages of process development (laboratory-, pilot-, and demonstrationscale) before it is implemented at commercial scale. Often the transition from early research to commercialization takes 10 years or more and requires large capital investment [5]. Reducing technology development time will enable faster access to markets. Technology development can be accelerated by coordinating efforts between multiple development teams working on different process technologies, such as catalytic conversion and separations. In this case, the economic performance of a new chemical process might be improved by developing a separation process that can be used to easily recover and recycle unconverted raw material, if it is difficult to improve the catalyst conversion. Technology development efforts tend to have an asymptotic return on investment, such that the economic benefit per dollar invested in improving process performance grows smaller. Determining the economic benefits of improving process parameter values will allow research and development teams to focus on improving those process parameters that have the potential to provide better economic performance.

A semi-quantitative method has been proposed by Patel et al. [6] that integrates economic and environmental indicators to provide a generic 'feasibility score' that is useful as a way to sift through many novel biorenewable chemical routes early in the development process [6]. This method, however, is not used to quantitatively assess the economic viability of a process for the production of the biorenewable chemical over a range of process parameters and to determine process trade-offs among process parameters. Understanding the consequences of process tradeoffs allows the setting of meaningful performance targets for the technology development team. 
This paper provides a new approach by combining feasible space analysis (FSA), TEA, and LCA methods to evaluate and guide the development of biorenewable chemical technologies. The shortcomings of existing approaches for the assessment of biorenewable chemical production processes can be overcome by combining these methods.

The FSA method maps the trade-offs in process parameters into production performance metrics, such as the production cost of a process. Such a mapping defines a "space" of process parameters that will result in a commercially viable process for chemical production. The FSA method has been used to optimize the cost performance of chemical processes $[7,8]$. In addition to cost considerations, new and existing chemical production processes must meet environmental objectives, as there is a growing concern over the increasing greenhouse gas (GHG) concentrations in the atmosphere [9]. Therefore, it would be useful to extend the FSA method to take environmental objectives into account, which has not been done before.

We used the minimum selling price (MSP) as an economic performance metric, and energy consumption and GHG emissions as environmental performance metrics [10]. The MSP of a biorenewable chemical that is synthesized using a biocatalyst, for example, is driven by the costs of feedstock, fermentor, and separations [11]. Feedstock cost is dominated by the yield of chemical per unit of feedstock and the price of feedstock [12]. The separations cost is driven by the product titer [13]. The production rates influence the capital and operating costs of the fermentor [14]. Similar to the MSP, the GHG emissions and the energy consumption of a biocatalytic process are largely influenced by productivities, titers, and yields. The feedstock production might cause the largest life cycle environmental impact in the biorenewable chemical production system. The yield determines the amount of feedstock required for making the chemical and thus the feedstock contribution to the overall energy consumption and GHG 
emissions. The energy requirement of the fermentation process depends on the agitator power $(\mathrm{kW})$, which, in turn, depends on production rates. The fermentation titer impacts the energy demand and GHG emissions of downstream processes.

In the current work, the production of fatty acid from glucose using Escherichia coli (E. coli) was used as a model system to demonstrate the assessment of a new biorenewable chemical process by combining the methods of FSA, TEA, and LCA. Fatty acids are platform molecules that can be transformed into a range of industrial chemicals, such as fatty alcohols [15], $\alpha$-olefins [16], ethyl esters [17], and alkanes [18]. Global consumption of fatty acids is increasing at a rate of 3\% annually [19]. Currently, fatty acids are primarily made from natural oils, such as coconut oil [20]. The hydrolysis of these natural oils results in a mixture of fatty acids that is further fractionated into pure fatty acids. The environmental impact of conventional fatty acid production is high, as the fractionation process consumes large amounts of fossil energy [20]. The new market opportunities for fatty acids and negative environmental impacts of the conventional process have driven interest towards developing efficient biocatalysts to synthesize fatty acids from sugars [21]. Producing fatty acids in a microorganism would allow tailoring properties, such as chain length and functionality, which can add special value by addressing the needs of specific industries, such as the detergent industry [22].

In this work, capric acid was used as a model fatty acid molecule. A process flow diagram (PFD) for the synthesis of capric acid was developed. The PFD was modeled to determine material and energy balances of the capric acid production process for various combinations of yield, titer, and volumetric productivity. These balances were used to estimate MSP, energy use, and GHG emissions of the capric acid production process. Such estimates were utilized to generate cost, energy, and GHG performance surfaces. Finally, a feasible space 
for the glucose-based capric acid production process in terms of yield, titer, and productivity was defined using performance surfaces and constraint planes of cost, energy, and GHG. The constraint planes were determined by estimating performance metrics of the coconut-oil-derived capric acid production process. The assessment of glucose-based capric acid production by combining FSA, TEA, and LCA indicated that this process has the potential to compete with the conventional technology in terms of economic and environmental performances. However, the biocatalyst development team must achieve capric acid yield from glucose of greater than $0.25 \mathrm{~g}$ $\mathrm{g}^{-1}$ and a titer greater than $40 \mathrm{~g} \mathrm{l}^{-1}$ if the process is to meet the performance of the conventional technology in terms of cost, energy use, and GHG emissions.

\section{Process Description and Modeling}

In the patent published in 2014 by San and Han, a strain of E. coli was used to synthesize capric acid from glucose [21]. The biocatalyst development team has attained a capric acid yield of $0.25 \mathrm{~g} \mathrm{~g} \mathrm{~g}^{-1}$, a volumetric productivity of $0.8 \mathrm{~g} \mathrm{l}^{-1} \mathrm{~h}^{-1}$, and a titer of $15 \mathrm{~g} \mathrm{l}^{-1}$ (personal communication from the development team). We created a PFD of this process (Fig. 1). An annual plant capacity of 40,000 metric tons of glucose conversion and a plant life of 20 years were assumed. The PFD has three major sections: seed fermentation, product fermentation, and separation/purification, which are described in detail in the following subsections.

\subsection{Seed fermentation section}

The E. coli strain is cultivated under microaerobic conditions on Luria Bertani (LB) medium in a seed fermentation train consisting of a series of fermentors [23]. The first fermentor in the seed fermentation train, with a volume of $10 \mathrm{~L}$, is inoculated with an E. coli cell culture grown in a 1-L laboratory-scale fermentor. After the cells reach a particular density, the cell broth is transferred to the next reactor in the seed fermentation train, and so on. After attaining 
the required cell density for the inoculation of the production fermentors, the E. coli cell broth from the final seed reactor is sent to the production fermentor.

SuperPro Designer ${ }^{\circledR}$ simulation software was used to simulate the seed fermentation train. The material and energy balances and the volumes of seed fermentors were estimated from these simulations. The growth of $E$. coli in the seed fermentation train was modeled using conventional Monod kinetics. A value of $0.4 \mathrm{~h}^{-1}$ was used for the maximum specific growth rate. The yield coefficient of biomass from glucose was taken as $0.5(\mathrm{~g} \mathrm{dcw})(\mathrm{g} \text { glucose })^{-1}$. The seed reactors were assumed to be operating in batch mode with a turnaround time of $6 \mathrm{~h} \mathrm{[24].}$

\subsection{Product fermentation section}

The microbial inoculum from the final fermentor of the seed fermentation train is fed to the production fermentor. The production fermentor is operated in fed-batch mode by feeding glucose. In the production fermentor, $E$. coli synthesizes capric acid from glucose and secretes it into the fermentation broth. The production of capric acid is carried out under microaerobic conditions on minimal medium. The temperature of the production fermentor is maintained at 37 ${ }^{\circ} \mathrm{C}$. A base is added to the fermentor to maintain a $\mathrm{pH}$ of 5 as the production of capric acid would otherwise cause a decrease in $\mathrm{pH}$.

The production fermentor was modeled using SuperPro Designer ${ }^{\circledR}$ to estimate its volume. Capric acid was assumed to be a fully growth-associated product (i.e., the specific rate of capric acid production is directly proportional to the specific growth rate) [25]. The values for

maximum specific growth rate, biomass yield, and capric acid yield were taken as $0.1 \mathrm{~h}^{-1}, 0.05(\mathrm{~g}$ $\mathrm{dcw})(\mathrm{g} \text { glucose })^{-1}$, and $0.38(\mathrm{~g})(\mathrm{g} \text { glucose })^{-1}$, respectively. 


\subsection{Separation and purification section}

The fermentation broth containing capric acid, water, nutrients, and other impurities is sent to a rotary vacuum filter (RVF). We modeled a RVF with a microporous filter medium, such as a membrane filter, and with the use of diatomaceous earth as a filter aid to remove $E$. coli cells from the fermentation broth [26-28]. A filtration time of $30 \mathrm{~h}$, a filtration flux rate of $250 \mathrm{l} \mathrm{m}^{-2} \mathrm{~h}^{-}$ ${ }^{1}$, and a filter cake level of dryness (LOD) of 30 were used in the modeling of the RVF, using SuperPro Designer ${ }^{\circledR}$. The retentate of filtration, containing microbial cells and other solids, is discharged as a waste stream. The flow rates of retentate and filtrate and filter membrane area were estimated using cake dryness and filtration time data.

The capric acid can be extracted from the clarified fermentation broth by solvation with $n$-hexane. The reader is referred to the supplementary information about details of the solvent selection criteria and the modeling of the solvent extraction process. SuperPro Designer ${ }^{\circledR}$ was used for the simulation of the solvent extraction column. The volumetric flow rates of the raffinate and extract phases of the column, the diameter of the column, and the number of stages were estimated from the simulation.

The extract phase, containing $n$-hexane, capric acid, and a very small amount of water, is sent to a distillation column. Distillation is utilized to recover the $n$-hexane. The $n$-hexane and water mixture is collected as a condensate at the top of the distillation column. This mixture is recycled to the solvent extraction column. The capric acid is recovered from the reboiler at the bottom of the distillation column. Aspen Plus ${ }^{\circledR}$ was used to simulate the distillation column because it provides sophisticated models (such as RadFrac) that can be used to model distillation columns rigorously. 
The very small amount of $n$-hexane, dissolved in the continuous phase of the solvent extraction column, can be recovered using an evaporation column or a decanter. The top vapor stream of the evaporation column containing $n$-hexane is sent to a condenser. The evaporator and condenser processes were modeled using Aspen Plus ${ }^{\circledR}$. The parameters for the evaporation column were determined using vapor-liquid equilibrium data of $n$-hexane and water mixtures. The Non-random two-liquid model (NRTL) was used to generate such equilibrium data. The shell and tube model in Aspen Plus ${ }^{\circledR}$ was chosen to model the condenser.

\subsection{Estimation of microbial capric acid MSP}

The built-in cost models in the SuperPro Designer ${ }^{\circledR}$ were used to estimate the equipment costs of the seed and production fermentors, the RVF filter, and the solvent extraction column. The cost of the distillation column was estimated on the basis of the type of tray, the number of trays, and the tower diameter [29]. A cost correlation between purchase-cost and the outside surface area of the tubes was used to calculate the costs of the condenser, the reboiler, and other heat transfer equipment [30]. The purchase cost of the centrifuge was estimated using an empirical equation based on the diameter [30]. The equipment costs were updated to U.S. 2015 prices using chemical engineering plant cost indices. The ratio factors based on delivered equipment cost were used to estimate the fixed-capital investment for the capric acid production plant [29].

The required quantities of raw materials and utilities were calculated using the simulated material and energy balances. The prices of glucose, $n$-hexane, natural gas, and electricity were assumed as $\$ 0.30 \mathrm{~kg}^{-1}, \$ 0.40 \mathrm{~kg}^{-1}, \$ 3.35 \mathrm{MMBtu}^{-1}$, and $\$ 0.07 \mathrm{kWh}^{-1}$, respectively. The long term mean prices of electricity and natural gas were used in the calculation. These average values were estimated from the 2007-2015 data of electricity and natural gas prices in the U.S. [30,31]. 
The $n$-hexane price was obtained from the pure component database of SuperPro Designer ${ }^{\circledR}$. The price of glucose was obtained from the managers of corn wet milling plants in the Midwest region of the U.S. (personal communication). Sugars can be made from various feedstocks, including lignocellulosic and corn. Currently, high capital costs and immaturity of the technology make the production of sugars from lignocellulosic feedstock economically unviable [32,33]. In addition, the use of impure lignocellulosic-derived sugars increases the downstream separation and purification costs of chemical production. We chose glucose derived from corn starch as a currently available, low cost feedstock suitable for capric acid production in North America.

A correlation between the plant capacity and the operating labor was used to determine labor charges [34]. The costs associated with maintenance and operating overheads were assumed as $8 \%$ and $23 \%$ of total purchased equipment cost and labor cost, respectively [34]. Wastewater treatment was assumed to take place in an external facility for a fee of $\$ 0.22$ per $\mathrm{kg}$ of organic material removed [34]. The calculations for the depreciation of capital investment were carried out using the Modified Accelerated Cost Recovery Systems (MACRS) method [34]. The general expenses were calculated as $10 \%$ of total revenues generated from the sales of capric acid [34]. An economic model was built using the estimated capital and operating costs. The discounted cash flow analysis method was used to estimate the MSP of capric acid [10]. A discount rate of $10 \%$ has chosen for this analysis [10]. The MSP of capric acid was calculated for various combinations of titers, yields, and volumetric productivities.

\subsection{Estimation of GHG emissions and energy consumption}

The GHG emissions and energy consumption of the process for the production of capric acid from glucose were estimated using the LCA approach. The functional unit was defined as 1 
$\mathrm{kg}$ of capric acid made from corn. The system boundaries include cultivation of corn, conversion of corn to glucose through the corn wet milling process, and the microbial synthesis of capric acid from glucose.

The $\mathrm{CO}_{2}$ emissions associated with corn grain production and the corn wet milling process to convert corn into glucose were obtained from Akiyama et al. [35] as $0.15(\mathrm{~kg})(\mathrm{kg}$ glucose $)^{-1}$ and $0.35(\mathrm{~kg})(\mathrm{kg} \text { glucose })^{-1}$, respectively. The value of $\mathrm{CO}_{2}$ absorbed by corn plants from the air was accounted as $1.47(\mathrm{~kg})(\mathrm{kg} \text { glucose })^{-1}$ [35]. This value was estimated from the stoichiometry of glucose formation by corn plants from water and $\mathrm{CO}_{2}$. It requires a total of 7.5 MJ to make $1 \mathrm{~kg}$ of glucose from corn, which includes the energy requirements for corn planting, cultivating, harvesting, and wet milling [35]. The mass ratio allocation method was used to allocate process flows among the products of the corn wet milling process [35]. The electricity and steam requirements, which were estimated from the simulation of the process, were utilized to determine the energy consumption and GHG emissions associated with the production of capric acid from glucose. The lifecycle energy for producing $1 \mathrm{MJ}$ of electricity and steam from natural gas in the U.S. and corresponding GHG emissions were found in the Ecoinvent database [36].

\subsection{Estimation of selling price, GHG emissions, and energy consumption of coconut-oil-} derived capric acid

A mixture of capric acid, octanoic acid, palmitic acid, and lauric acid and glycerol is formed when coconut oil is hydrolyzed [37]. The by-product glycerol is separated from the mixture of fatty acids using a distillation column [37]. The fatty acid mixture is then fractionated into capric, octanoic, palmitic, and lauric acids using fractional distillation column [37]. We did 
not perform economic analysis of the conventional process for capric acid production, as the market price of capric acid is available from ICIS chemicals [38].

The environmental performance metrics of conventional production were estimated using the LCA approach. The functional unit was defined as $1 \mathrm{~kg}$ of capric acid made from coconut oil. The system boundaries include cultivation of coconuts, production of oil from coconuts, and the synthesis of capric acid from coconut oil. The life cycle inventories for processes of cultivation of coconuts and extraction of oil from coconuts were found in the Ecoinvent database [36]. The $\mathrm{CO}_{2}$ uptake by coconut trees and the GHG emissions of the coconut oil production process were taken as $0.0097(\mathrm{~kg})(\mathrm{kg} \text { capric acid) })^{-1}$ and $0.23\left(\mathrm{~kg} \mathrm{CO}_{2}\right.$ eq.) (kg capric acid) ${ }^{-1}$, respectively, for the calculation of the GHG emissions of the conventional process [36]. The GHG emissions of process for the production $\mathrm{n}$ of capric acid from coconut oil were estimated as 0.29 ( $\mathrm{kg} \mathrm{CO}_{2}$ eq.) $(\mathrm{kg} \text { capric acid })^{-1}$. This value was estimated using the process energy requirement of capric acid production from coconut oil. The material and energy balance data for hydrolysis, distillation, and fractionation processes were obtained from Gervajio [37]. The overall energy consumption and GHG emissions of the conventional process were allocated among capric, octanoic, palmitic, and lauric acids based on their concentrations in the fatty acid mixture.

\section{Results}

Since it is difficult to graph and visualize the multi dimensional performance surfaces that represent the effect of three or more variable process parameters on a performance metric, a three-dimensional representation is used. Based upon a personal communication from the Center for Biorenewable Chemicals (CBiRC) Scientific Advisory Board, a rule-of-thumb volumetric productivity target for a bulk chemical via microbial synthesis is $1-3 \mathrm{~g} \mathrm{l}^{-1} \mathrm{~h}^{-1}$. The results of the economic analysis indicate that volumetric productivities greater than $2 \mathrm{~g} \mathrm{l}^{-1} \mathrm{~h}^{-1}$ have a small 
effect on the cost of capric acid production. For a given yield and titer, the production cost of making capric acid is reduced only by $5 \%$ when the volumetric productivity is increased from 2 $\mathrm{g} \mathrm{l}^{-1} \mathrm{~h}^{-1}$ to $3 \mathrm{~g} \mathrm{l}^{-1} \mathrm{~h}^{-1}$. The economic and environmental performance metrics of capric acid production are, therefore, estimated for a wide range of titers and yields and a constant volumetric productivity of $2 \mathrm{~g}^{-1} \mathrm{~h}^{-1}$. The lower and upper bounds for yield and titer are assumed to be 10 and $100 \%$ of the maximum yield of capric acid and 10 and $200 \mathrm{~g} \mathrm{l}^{-1}$, respectively.

\subsection{Energy, GHG, and cost performance surfaces}

Performance surfaces for energy and GHG are generated by mapping energy consumption and GHG emissions to the corresponding titers and yields, respectively (Fig. 2a and Fig. 2b). The performance cost surface is created by plotting minimum selling prices on the $\mathrm{z}$ axis and corresponding yields and titers on the $\mathrm{x}$ - and $\mathrm{y}$-axes, respectively (Fig. 2c). For a given titer, the MSP, energy consumption, and GHG emissions of the capric acid production process are inversely related to yields (Fig. 2a, 2b, and 2c). In addition, the performance energy, GHG, and cost surfaces of capric acid production have a similar shape (Fig. 2a, 2b, and 2c). This indicates that the MSP, energy consumption, and GHG emissions of capric acid production are highly correlated. In other words, replacing corn with another feedstock, in an effort to reduce the total energy consumption of the process for capric acid production, will also increase or decrease the production cost.

A percentage change in the value of the yield will have a higher impact on performance metrics of capric acid production than the same percentage change in the value of the titer. For example, there is a nearly $500 \%$ increase in the total energy consumption as the capric acid fermentation yield drops from $0.38 \mathrm{~g} \mathrm{~g}^{-1}$ to $0.04 \mathrm{~g} \mathrm{~g}^{-1}$ for a given titer (Fig. 2a). On the other hand, for a given yield, there is only a $100 \%$ increase in energy consumption when the titer falls 
from $200 \mathrm{~g}^{-1}$ to $20 \mathrm{~g}^{-1}$ (Fig. 2a). This is because any change in the value of the fermentation yield will have an effect on the entire upstream part of the capric acid production chain, including corn agriculture, glucose production from corn, and the fermentation processes.

When titers are low and yields are high, the variation in titer affects the energy consumption, GHG emissions, and MSP of the capric acid production process more than the yield does (Table 1). The energy consumption of the separation and purification processes dominates the overall energy consumption of the capric acid production process for low titers because of the high energy requirement to evaporate the large amount of water that is associated with low titers. Such a high energy requirement is the reason why low titers are associated with high production cost and high GHG emissions.

\subsection{Energy, GHG, and cost feasible spaces}

The cradle-to-gate energy consumption of the coconut-oil-derived capric acid production process is estimated as $49 \mathrm{MJ} \mathrm{kg}^{-1}$, which is used to determine the constraint energy plane seen in Fig. 3a. The space between the energy performance surface and the constraint energy plane is referred to as the energy feasible space (Fig. 3a). We refer to the curve resulting from the intersection of the performance surface and the constraint plane as the feasible energy curve (Fig. 3a). For combinations of yield, titer, and volumetric productivity within the energy feasible space, the glucose-based capric acid production consumes an amount of energy that is less than or equal to that consumed in conventional capric acid production. This is because the use of a $E$. coli strain that can synthesize capric acid with a high selectivity avoids the requirement for the highly energy-intensive fractionation process that is used in the conventional process. In addition, the energy required to make glucose is less than that required to make coconut oil (data not shown). 
The GHG space is created by determining the GHG constraint plane (Fig. 3b). The cradle-to-gate GHG emissions of conventional capric acid production are estimated as $0.51(\mathrm{~kg}$ $\mathrm{CO}_{2}$ eq.) (kg capric acid $)^{-1}$. The GHG emissions of the glucose-based capric acid production process are found to be negative for some combinations of process parameters (Fig. 3b). These negative emissions occur because the cradle-to-gate GHG emissions associated with capric acid production are less than the fixation of $\mathrm{CO}_{2}$ into glucose by the growing corn plants. When capric acid is converted into products like fuel, the carbon stored in the capric acid is emitted as $\mathrm{CO}_{2}$ during combustion. In such a case, the GHG emissions of the capric acid production process must be estimated without considering the value of $\mathrm{CO}_{2}$ fixation as glucose.

The environmental impact of capric acid production will be low if the microorganism exhibits a high capric acid yield. This is because the formation of by-products significantly affects the GHG emissions of capric acid production. The minimum GHG emissions of $-0.95(\mathrm{~kg}$ $\mathrm{CO}_{2}$ eq.) (kg capric acid) $)^{-1}$ are determined for a fermentation titer of $200 \mathrm{~g} \mathrm{l}^{-1}$, a volumetric productivity of $2 \mathrm{~g} \mathrm{l}^{-1} \mathrm{~h}^{-1}$, and a yield of $0.38 \mathrm{~g} \mathrm{~g}^{-1}$ (Fig. 3b). The GHG emissions of capric acid production are increased to $34 \mathrm{~kg} \mathrm{CO}_{2}$ eq. when the yield drops to $0.04 \mathrm{~g} \mathrm{~g}^{-1}$ (Fig. 3b). Such a large increase in the amount of GHG emitted is due to the formation of by-products. In this analysis, the by-product stream is assumed to be discharged as a waste sludge, and this sludge is treated at an external waste water treatment facility. The carbon present in the by-products can be oxidized to $\mathrm{CO}_{2}$ and $\mathrm{H}_{2} \mathrm{O}$ in the wastewater treatment plant using the aerobic digestion process [39].

The market price of capric acid is $\$ 1.50 \mathrm{~kg}^{-1}$ [38], which is used to determine the cost constraint plane (Fig. 3c). The space between the cost performance surface and the constraint cost plane is referred as the cost feasible space (Fig. 3c). The MSP of glucose-based capric acid 

investors expect high return on investment (i.e. high profits) when there is a high investment risk. The cost feasible space shows obtainable profits with the production of capric acid using a biocatalyst for a wide range of process parameters (Fig. 3c). For a given investment risk, the cost feasible space can be utilized to determine titer, yield, and productivities that are necessary to generate the expected return on investment for the production of capric acid at a commercial scale. For example, if investors are expecting a profit of $\$ 0.30$ per $\mathrm{kg}$ capric acid when there is a high investment risk, it is necessary to develop a biocatalyst that produces capric acid at a yield of $0.38 \mathrm{~g} \mathrm{~g}^{-1}$, a titer of $200 \mathrm{~g} \mathrm{l}^{-1}$, and a volumetric productivity of $2 \mathrm{~g} \mathrm{l}^{-1} \mathrm{~h}^{-1}$ (Fig. 3c).

The feasible cost space can be used to guide the choice of a viable target molecule from the set of possible products that can be made from capric acid. For example, capric acid can be converted into 1-decanol via hydrogenation [37] and 1-nonene via decarbonylation [2]. The average market prices are $\$ 2.20 \mathrm{~kg}^{-1}$ for 1 -decanol and $\$ 1.50 \mathrm{~kg}^{-1}$ for 1 -nonene [38]. The cost 
feasible space shows that a production cost of at least $\$ 1.20$ is necessary to synthesize one $\mathrm{kg}$ of capric acid from glucose (Fig. 3c). The feedstock (capric acid) contributions to the overall cost of 1-decanol and 1-decene production are $\$ 1.32 \mathrm{~kg}^{-1}$ and $\$ 1.64 \mathrm{~kg}^{-1}$, respectively. The feedstock cost contribution is estimated using practical yields that are based on conversion of capric acid. The margins left for energy and other operating costs of 1-decanol and 1-decene production are $\$ 0.88$ and $-\$ 0.14$, respectively, after subtracting the feedstock cost from the market prices of 1decanol and 1-decene. Such a simple analysis indicates that the development of a technology for converting capric acid into 1-decanol is clearly a promising option. On the other hand, the negative margin indicates that development of a process for the production of 1-decene is economically unviable.

As shown in Fig. 3a, 3b, and 3c, the GHG feasible space is larger than the feasible spaces for energy and cost. In other words, there are more combinations of yield, titer, and productivity for which capric acid production meets the GHG constraint than there are combinations that meet the energy and cost constraints. However, capric acid production is considered to be economically and environmentally viable for a combination of process parameters only when the production meets all three constraints. In order to determine the combinations of process parameters that meet all three constraints, we define the two dimensional (2D) feasible space of capric acid production using energy, GHG, and cost feasible curves, the maximum biosynthesis pathway yield, the maximum assumed titer, and the fixed volumetric productivity.

\subsection{D-feasible space of the microbial capric acid process}

The 2D-feasible space is defined for the glucose-based capric acid production by graphing the energy, GHG, and cost feasible curves in addition to the maximum yield and titer constraints (Fig. 4). The existence of a feasible space indicates that the glucose-based capric acid 

production can be achieved through many different routes. For example, one route is to push the capric acid yields from $0.25 \mathrm{~g} \mathrm{~g}^{-1}$ to $0.38 \mathrm{~g} \mathrm{~g}^{-1}$, the volumetric productivity from $0.8 \mathrm{~g}^{-1} \mathrm{~h}^{-1}$ to $2 \mathrm{~g}$ $\mathrm{l}^{-1} \mathrm{~h}^{-1}$, and the titer from $15 \mathrm{~g} \mathrm{l}^{-1}$ to $40 \mathrm{~g} \mathrm{l}^{-1}$ (Fig. 4). Another route is to achieve titers of greater 

(Fig. 4).

The performance targets will be determined by identifying the best route from all possible routes. The best route can be identified by comparing, among the possible routes, the development time and costs that are necessary to achieve an economically and environmentally viable process for capric acid production via each possible route. The research and management teams can qualitatively estimate the development times and costs for each route. The technological barriers and uncertainties that thwart attempts to improve fermentation yields, titers, and volumetric productivities will impact the amount of time and money necessary for achieving the performance targets. The resources necessary to push the performance level of a biocatalyst will be high in the presence of technological barriers. Further research is necessary to develop an analytic method or a framework that can be used to quantify the amount of time and the cost required to push the currently attainable yields, titers, and productivities in order to meet the performance targets.

In addition to the trade-offs, the feasible space in Fig. 4 shows that there is a small effect of increase in a capric acid titer greater than $100 \mathrm{~g} \mathrm{l}^{-1}$ on the MSP, GHG emissions, and energy consumption of the process. Hence, the financial resources must be directed to improving biocatalyst yields or production rates after the development team has managed to achieve a titer of greater than $100 \mathrm{~g} \mathrm{l}^{-1}$ (Fig. 4). The results of feasible space analysis, therefore, can be utilized to optimize the resources of time and money required for the development of the biocatalyst for capric acid production.

The fermentation metrics of at least $0.25 \mathrm{~g} \mathrm{~g}^{-1}$ yield and $40 \mathrm{~g} \mathrm{l}^{-1}$ titer are desirable for commercial relevance (Fig. 4). During scale up of capric acid production from laboratory- to 
pilot- and then to commercial scale, there is a possibility of performance loss, due to technical risks [41]. For example, in the case of aerobic fermentations, difficulties in maintaining the desired dissolved oxygen concentration in a commercial-scale fermentor could reduce the performance levels of a microbial strain to values below those obtained in the laboratory-scale fermentor. If such technical risks make it impossible to achieve biocatalyst yields of $\geq 0.25 \mathrm{~g} \mathrm{~g}^{-1}$ or titers of $\geq 40 \mathrm{~g} \mathrm{l}^{-1}$, the development of a biocatalyst becomes unviable. In such a situation, it is highly desirable to stop further development of the strain. There is no methodology in the literature for quantifying such performance losses during the scale-up of a process for the production of a biorenewable chemical. Experts in biomanufacturing, however, can estimate such performance losses qualitatively from their experience of technology de-risking.

Figure 4 shows that the feasible GHG and energy curves of capric acid production are below the feasible cost curve. This indicates that capric acid production is environmentally sustainable if it achieves economic viability, but the opposite may not be true. Since the cost of the feedstock (glucose) dominates the overall production cost (Fig. S1), it may be possible to shift the feasible cost curve to below the energy and GHG curves by developing a biocatalyst that can synthesize capric acid from an inexpensive feedstock.

Variation of the feasible space boundary in Fig. 4 can be caused by the price volatility of glucose, natural gas, electricity, solvent, and capric acid [40]. Such a variation can be used to indicate the financial risk associated with the investment for producing biorenewable chemicals: there will be a low financial risk for producing capric acid if the variation of the feasible space boundary of capric acid production is low. The variation of the feasible space boundary can be quantified using a procedure based on Monte-Carlo simulation [42].

\subsection{Sensitivity analysis}


The feasible space in Fig. 4 shows how different values of titer and yield impact MSP, GHG emissions and the energy consumption of capric acid production. The feasible space analysis cannot show the impact that changes in a certain process assumption will have on the performance metrics of capric acid production. Thus, a sensitivity analysis is performed to identify process parameters that are key drivers of performance metrics of capric acid production. A fermentation yield of $0.36 \mathrm{~g} \mathrm{~g}^{-1}$, a volumetric productivity of $2 \mathrm{~g} \mathrm{l}^{-1} \mathrm{~h}^{-1}$, and a fermentation titer of $75 \mathrm{~g} \mathrm{l}^{-1}$ are selected to perform the sensitivity analysis. The results of this analysis are also applicable to all feasible combinations of yields, titers, and volumetric productivities because we used the same assumptions when estimating the performance metrics of capric acid production over a range of process parameters.

The variation of the MSP is measured for a $\pm 10 \%$ change in the prices of glucose, natural gas, and electricity, in the plant capacity, in the wastewater treatment cost, in the media cost, and in the fermentation turnaround time (Fig. S2). The results of the sensitivity analysis show that the MSP of capric acid is most sensitive to the glucose price. A $10 \%$ increase in the glucose price results in a $5 \%$ increase in the MSP of capric acid (Fig. S2). The plant capacity and the wastewater treatment cost have moderate impact on the capric acid MSP. A 3\% decrease in the value of capric acid MSP is observed for a $10 \%$ increase in the value of plant capacity. The capric acid MSP is increased by $1 \%$ when the wastewater treatment cost per $\mathrm{kg}$ of organic material removed is increased from $\$ 0.22$ to $\$ 0.24$. The sensitivity analysis shows that the impact of natural gas and electricity prices on capric acid MSP is not significant (Fig. S2).

A variation in the values of $\mathrm{CO}_{2}$ intake from air by corn plants is found when comparing the data of Weidema et al. [36] and Akiyama et al. [35]. The GHG emissions of steam and electricity generation vary with the type of fuel used for their production. Thus, the sensitivity of 
GHG emissions associated with capric acid production is measured both for a $\pm 10 \%$ change in the GHG emissions associated with the production of utilities and for a $\pm 10 \%$ change in $\mathrm{CO}_{2}$ intake (Fig. S3). A change in the value of $\mathrm{CO}_{2}$ intake causes the most variation in the GHG emissions associated with capric acid production.

The sensitivity of overall energy consumption of capric acid production is measured for a $\pm 10 \%$ change in the energy requirement values of the seed and production fermentations, and of the extraction, distillation, evaporation and glucose production processes. The process energy requirements of the fermentation and purification processes are considered in the analysis to determine the effect of uncertainties associated with the results of the Aspen Plus ${ }^{\circledR}$ and SuperPro Designer ${ }^{\circledR}$ process simulations. The energy required to make glucose from corn is the major parameter affecting the overall energy consumption (Fig S5). An $8 \%$ increase in the value of overall energy consumption results from a $10 \%$ increase in the value of the energy requirement of glucose production (Fig. S4).

\section{Discussion}

This work represents the first time that FSA, TEA, and LCA methods have been combined in the evaluation of a process for the production of a biorenewable chemical. In general, a single combination of process parameters is used while evaluating the economic and environmental performances of processes for the production of new biorenewable chemicals $[3$, 43-45]. For example, Efe et al. [3] assessed the economic viability of the succinic acid production process for a yield of 0.69 (g succinic acid) (g glucose) ${ }^{-1}$, a specific productivity of 89 $\mathrm{g} \mathrm{kg}^{-1} \mathrm{~h}^{-1}$, and a titer of $13.7 \mathrm{~g} \mathrm{l}^{-1}$. Under this combination of process parameters, the succinic acid production process is unviable, as the estimated MSP of succinic acid is greater than the market price of succinic acid. However, although the improvement of key process parameters 
might make this process viable, an analysis using a single combination of process parameters will not help to focus attention on the improvement of key process parameters.

Patel et al. [6] reported a method to evaluate a new biobased process at an early development stage. Their method considers only one process parameter, namely theoretical yield, while assessing the environmental performance of the new biobased process against the conventional chemical process. Such an assessment is not sufficient because the energy consumption and GHG emissions of biocatalytic processes depend on the titer and the volumetric productivity, along with the yield. Also, their method uses process costs and the environmental impact (PCEI) index as a proxy for indicating overall production costs of a new process for the production of a biorenewable chemical. The qualitative nature of the PCEI index introduces uncertainty into the assessment of economic viability of the process.

In this paper, we introduced a new approach by combining FSA, TEA, and LCA. This combined analysis provides an alternative to the qualitative and the single-process-configuration approaches for evaluating processes for the production of biorenewable chemicals. The feasible space of a biorenewable chemical route can be defined in four steps. The first step is to create a PFD for the production of the chemical. The second step consists of modeling the PFD to estimate performance metrics (MSP, energy consumption, and GHG emissions) of the production system for a wide range of process parameters. Performance surfaces for cost, energy, and GHG are generated by plotting a performance metric on the z-axis and corresponding process parameters on the $\mathrm{x}$ - and $\mathrm{y}$-axes. The third step is to estimate the production cost, the energy consumption, and the GHG emissions of the competing route. The performance metrics of the competing route are then used to determine constraint planes for cost, energy, and GHG. The intersections between the performance surfaces for cost, energy, and GHG and the constraint 
planes for cost, energy, and GHG are used to produce the feasible cost, energy, and GHG boundaries, respectively. When these feasible curves are plotted, the area inside the boundaries defines the feasible space for the biorenewable chemical route in step 4 .

The analysis of a biorenewable chemical process by combining FSA, TEA, and LCA analysis enables one to determine the process viability under all reasonable combinations of process parameters. If it is determined that the analyzed biorenewable chemical process is unviable for all combinations of process parameters, then further development of the process for the production of the new biorenewable chemical must be stopped to avoid probable losses of capital investments. The feasible space of a biorenewable chemical production process shows trade-offs among process parameters that can be used to set goals for the further development of the process. The feasible space of a chemical process is used to determine values of process parameters for which the investments for further improvement of a new biorenewable chemical process will result in insignificant economic and environmental benefits.

\section{Acknowledgements}

The authors thank Prof. Thatcher Root for comments on this research. This work was supported by the National Science Foundation [grant No. EEC-0813570/1158833].

\section{References}

[1] M. Gavrilescu, Y. Chisti, Biotechnology-A sustainable alternative for chemical industry, Biotechnol. Adv. 23 (2005) 471-499. doi:10.1016/j.biotechadv.2005.03.004.

[2] J.A. Lopez-Ruiz, R.J. Davis, Decarbonylation of heptanoic acid over carbon-supported platinum nanoparticles, Green Chem. 16 (2014) 683-694. doi:10.1039/c3gc41287c.

[3] Ç. Efe, L.A.M. Van der Wielen, A.J.J. Straathof, Techno-economic analysis of succinic acid production using adsorption from fermentation medium, Biomass Bioenergy 56 (2013) 479492. doi:10.1016/j.biombioe.2013.06.002.

[4] B. Cok, I. Tsiropoulos, A.L. Roes, M.K. Patel, Succinic acid production derived from carbohydrates: An energy and greenhouse gas assessment of a platform chemical toward a bio-based economy, Biofuels Bioprod. Biorefining 8 (2014) 16-29. doi:10.1002/bbb.1427.

[5] R. Taylor, L. Nattrass, G. Alberts, P. Robson, C. Chudziak, A. Bauen, I.M. Libelli, G. Lotti, M. Prussi, R. Nistri, D. Chiaramonti, A.L. Contreras, H. Bos, G. Eggink, J. Springer, R. 
Bakker, R.V. Ree, From the sugar platform to biofuels and biochemicals: Final report for the European commission, Contract no. ENER/C2/423-2012/S12.673791, 2015.

[6] A.D. Patel, K. Meesters, H. Den Uil, E. De Jong, E. Worrell, M.K. Patel, Early-stage comparative sustainability assessment of new bio-based processes, ChemSusChem 6 (2013) 1724-1736. doi:10.1002/cssc.201300168.

[7] J.R. Joseph, A. Sinclair, N.J. Titchener-Hooker, Y. Zhou, A framework for assessing the solutions in chromatographic process design and operation for large-scale manufacture, $\mathrm{J}$. Chem. Technol. Biotechnol. 81 (2006) 1009-1020. doi:10.1002/jctb.1508.

[8] F.F. Furlan, C.B.B. Costa, A.R. Secchi, J.M. Woodley, R.C. Giordano, Retro-technoeconomic analysis: Using (bio)process systems engineering tools to attain process target values, Ind. Eng. Chem. Res. 55 (2016) 9865-9872. doi: 10.1021/acs.iecr.6b01757

[9] W.Y. Chen, J. Seiner, T. Suzuki, M. Lackner, Handbook of Climate Change Mitigation, Springer, New York, 2012.

[10] W. Short, D.J. Packey, T. Holt, A manual for the economic evaluation and energy efficiency and renewable energy technologies, NREL/TP-462-5173, Golden, Colorado, 1995.

[11] J.T. Claypool, R. Raman, A coarse techno-economic model of a combined fermentation catalysis route to sorbic acid, American society of agricultural and biological engineers annual international meeting, Dallas, Texas, 2012.

[12] T. Willke, K.D. Vorlop, Industrial bioconversion of renewable resources as an alternative to conventional chemistry, Appl. Microbiol. Biotechnol. 66 (2004) 131-142. doi:10.1007/s00253-004-1733-0.

[13] R.G. Harrison, P.W. Todd, S.R. Rudge, D.P. Petrides, Bioseparations Science and Engineering, first ed., Oxford university press, New York, 2002.

[14] P. Tufvesson, J. Lima-Ramos, M. Nordblad, J.M. Woodley, Guidelines and cost analysis for catalyst production in biocatalytic processes, Organ. Process Res. Dev. 15 (2011) 266-274. doi:10.1021/op1002165.

[15] E.J. Steen, Y. Kang, G. Bokinsky, Z. Hu, A. Schirmer, A. McClure, S.B. Del Cardayre, J.D. Keasling, Microbial production of fatty-acid-derived fuels and chemicals from plant biomass, Nature 463 (2010) 559-562. doi:10.1038/nature08721.

[16] D. Mendez-Perez, M.B. Begemann, B.F. Pfleger, Modular synthase-encoding gene involved in $\alpha$-olefin biosynthesis in Synechococcus sp. strain PCC 7002, Appl. Environ. Microbiol. 77 (2011) 4264-4267. doi:10.1128/AEM.00467-11.

[17] R. Kalscheuer, T. Stölting, A. Steinbüchel, Microdiesel: Escherichia coli engineered for fuel production, Microbiol. 152 (2006) 2529-2536. doi:10.1099/mic.0.29028-0.

[18] R.M. Lennen, D.J. Braden, R.A. West, J.A. Dumesic, B.F. Pfleger, A process for microbial hydrocarbon synthesis: Overproduction of fatty acids in Escherichia coli and catalytic conversion to alkanes, Biotechnol. Bioeng. 106 (2010) 193-202. doi:10.1002/bit.22660.

[19] D. Guzman, Oleochemicals: The next generation. www.agwest.sk.ca/kaizen/PBIO2013/deGuzmanPBIO2013_web.pdf, 2013(accessed February 2016).

[20] H. Stage, Fatty acid fractionation by column distillation: Purity, energy consumption and operating conditions, J. Am. Oil Chem. Soc. 61(1984) 204-214. doi: 10.1007/BF02678770.

[21] K.Y. San, S. Han, Short chain fatty acids from bacteria, Patent no. US 20140212935 A1, 2014.

[22] F. Jing, D.C. Cantu, J. Tvaruzkova, J.P. Chipman, B.J. Nikolau, M.D. Yandeau-Nelson, P.J. Reilly, Phylogenetic and experimental characterization of an acyl-ACP thioesterase family 
reveals significant diversity in enzymatic specificity and activity, BMC Biochem. 12 (2011) 44.doi:10.1186/1471-2091-12-44.

[23] X. Zhang, M. Li, A. Agrawal, K.Y. San, Efficient free fatty acid production in Escherichia coli using plant acyl-ACP thioesterases, Metab. Eng. 13 (2011) 713-722. doi:10.1016/j.ymben.2011.09.007.

[24] D. Humbird, R. Davis, L. Tao, C. Kinchin, D. Hsu, A. Aden, P. Schoen, J. Lukas, B. Olthof, M. Worley, D. Sexton, D. Dudgeon, Process design and economics for biochemical conversion of lignocellulosic biomass to ethanol: Dilute-acid pretreatment and enzymatic hydrolysis of corn stover, NREL/TP-5100-47764, Golden, Colorado, 2011.

[25] E.M.T. El-Mansi, C.F.A. Bryce, A.L. Demain, A.R. Allman, Fermentation Microbiology and Biotechnology, second ed., Taylor \& Francis, New York, 2006.

[26] W.S. Gwak, S.W. Hong, S.A. Shin, H.W. Lee, Method for separating and purifying 1,4diaminobutane from fermented solution, Patent no. EP 2749649 A2, 2014.

[27] O.S. Fruchey, L.E. Manzer, D. Dunuwila, B.T. Keen, B.A. Albin, N.A. Clinton, B.D. Dombek, Processes for producing monoammonium adipate and conversion of monoammonium adipate to adipic acid, Patent no. US 8895779 B2, 2014.

[28] D.L. Woerner, Rotary drum filter, Patent no. US 6267889 B1, 2000.

[29] M.S. Peters, K.D. Timmerhaus, Plant Design and Economics for Chemical Engineers, fourth ed., McGraw-Hill Inc, New York, 1991.

[30] U.S. Energy Information Administration. https://www.eia.gov/electricity/monthly/epm_table_grapher.cfm?t=epmt_5_6_a, 2016 (accessed 8/9/16)

[31] U.S. Energy Information Administration. https://www.eia.gov/dnav/ng/hist/rngwhhdm.htm, 2016 (accessed 8/9/16)

[32] T. Dickerson, J. Soria, Catalytic fast pyrolysis: A review, Energies 6 (2013) 514-538. doi:10.3390/en6010514.

[33] D. Klein-Marcuschamer, P. Oleskowicz-Popiel, B.A. Simmons, H.W. Blanch, The challenge of enzyme cost in the production of lignocellulosic biofuels, Biotech. Bioeng. 109 (2012) 1083-1087. doi: 10.1002/bit.24370

[34] W.D. Seider, J.D. Seader, D.R. Lewin, S. Widagdo, Product and Process Design Principles: Synthesis, Analysis, and Evaluation, third ed., John Wiley \& Sons Inc, Hoboken, New Jersey, 2010.

[35] M. Akiyama, T. Tsuge, Y. Doi, Environmental life cycle comparison of polyhydroxyalkanoates produced from renewable carbon resources by bacterial fermentation, Polym. Degrad. Stab. 80 (2003) 183-194. doi:10.1016/S01413910(02)00400-7.

[36] B.P. Weidema, C. Bauer, R. Hischier, C. Mutel, T. Nemecek, J. Reinhard, C.O. Vadenbo, G. Wernet, Overview and methodology: Data quality guideline for the ecoinvent database version 3, Ecoinvent report, St. Gallen, Switzerland, 2013.

[37] G.C. Gervajio, Fatty acids and derivatives from coconut oil, Kirk-Othmer Encycl. Chem. Technol. (2012) 1-38. doi: 10.1002/0471238961.fattgerv.a01.

[38] ICIS Chemical Pricing. http://www.icis.com/about/price-reports/, 2014(accessed 08.20.14)

[39] F.Y. Cakir, M.K. Stenstrom, Greenhouse gas production: A comparison between aerobic and anaerobic wastewater treatment technology, Water Res. 39 (2005) 4197-4203. doi:10.1016/j.watres.2005.07.042. 
[40] S. Gunukula, P.L. Keeling, R. Anex, Risk advantages of platform technologies for biorenewable chemical production, Chem. Eng. Res. Des. 107 (2016) 24-33. doi:10.1016/j.cherd.2015.10.035.

[41] F.K. Kazi, J.A. Fortman, R.P. Anex, D.D. Hsu, A. Aden, A. Dutta, G. Kothandaraman, Techno-economic comparison of process technologies for biochemical ethanol production from corn stover, Fuel 89 (2010) S20-S28. doi:10.1016/j.fuel.2010.01.001.

[42] J.M.P. King, Y. Zhou, N.J. Tichener-Hooker, Quantification of robustness for bioprocess validation: A chromatography case-study using Monte-Carlo simulation, 9th International symposium on computer applications in biotechnology, Nice, France, 2004.

[43] J. Sikder, M. Roy, P. Dey, P. Pal, Techno-economic analysis of a membrane-integrated bioreactor system for production of lactic acid from sugarcane juice, Biochem. Eng. J. 63 (2012) 81-87. doi:10.1016/j.bej.2011.11.004.

[44] L.R. Castilho, C.M.S. Polato, E.A. Baruque, G.L. Sant'Anna Jr., D.M.G. Freire, Economic analysis of lipase production by Penicillium restrictum in solid-state and submerged fermentations, Biochem. Eng. J. 4 (2000) 239-247. doi:10.1016/S1369-703X(99)00052-2.

[45] L. Tao, E.C.D. Tan, R. McCormick, M. Zhang, A. Aden, X. He, B.T. Zigler, Technoeconomic analysis and life-cycle assessment of cellulosic isobutanol and comparison with cellulosic ethanol and n-butanol, Biofuels Bioprod. Biorefining 8 (2014) 30-48.

doi:10.1002/bbb.1431. 


\section{Figure captions}

Fig. 1. Proposed process for the production of capric acid from glucose.

Fig. 2. Performance surfaces of process for the production of capric acid from glucose (a) Energy performance surface (b) GHG performance surface and (c) Cost performance surface.

Fig. 3. Three-dimensional feasible space of process for the production of capric acid (a) Energy feasible space (b) GHG feasible space (c) and Cost feasible space.

Fig. 4. Two-dimensional feasible space for the production of capric acid from glucose bounded by titer, yield, and the cost curves for a constant volumetric productivity $\left(2 \mathrm{~g} \mathrm{l}^{-1} \mathrm{~h}^{-1}\right)$. 
Tables

Table 1

Dominant process sections of capric acid production.

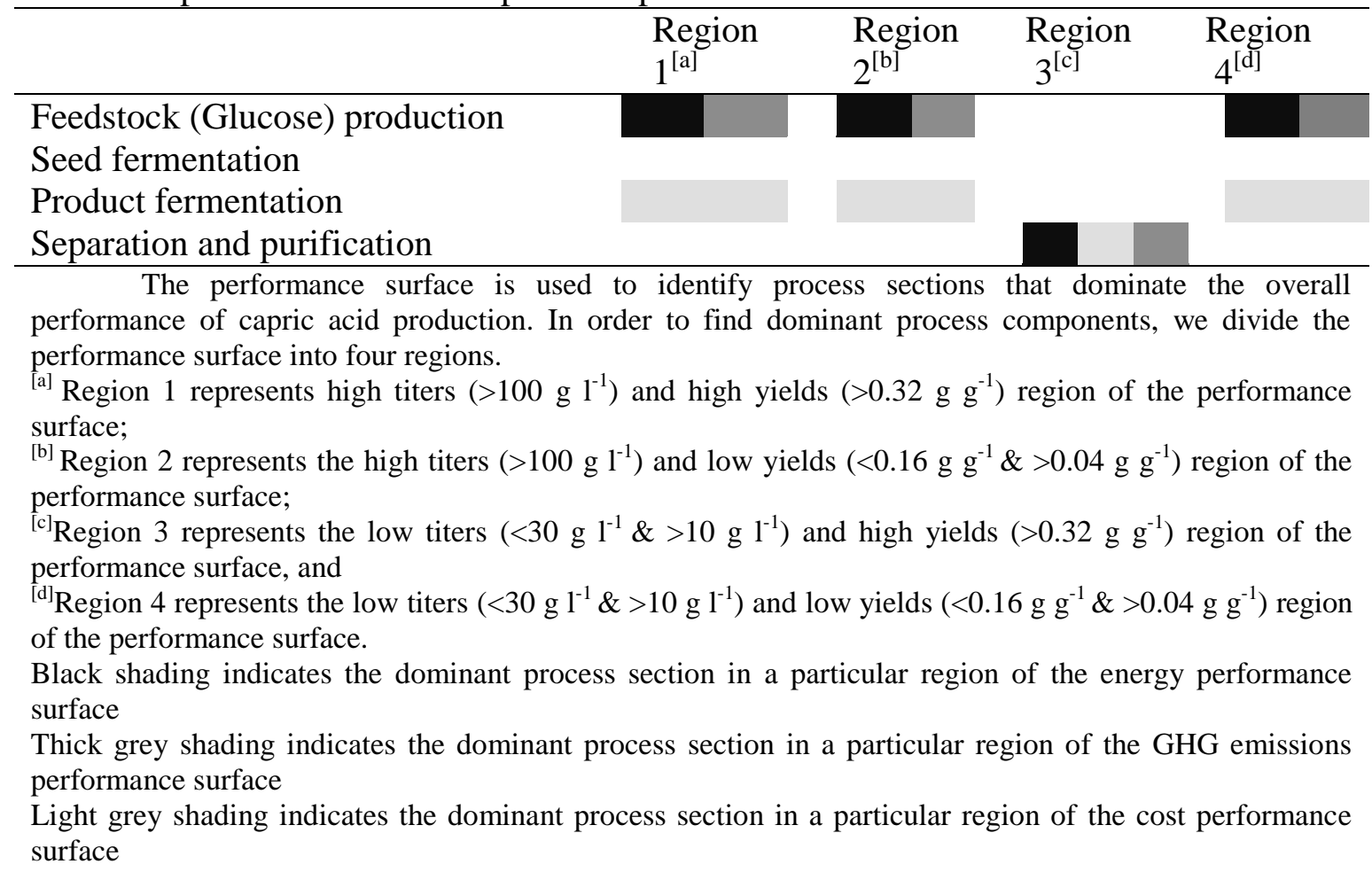




\section{Table 2}

Components of total capital investment for capric acid production.

\begin{tabular}{lc}
\hline & Million U.S. Dollars 2015 \\
\hline & 7.0 \\
Total equipment purchase cost (TEP) & 2.7 \\
Installation cost (39\% of TEP) & 3.0 \\
Instrumentation (43\% of TEP) & 2.1 \\
Piping (31\% of TEP) & 0.7 \\
Electrical (10\% of TEP) & 1.05 \\
Buildings (15\% of TEP) & 0.84 \\
Yard improvements (12\% of TEP) & 3.8 \\
Service facilities (55\% of TEP) & 21.4 \\
Total direct plant costs (TDC) & \\
& \\
Indirect costs & 2.24 \\
Engineering \& Supervision (32\% of TEP) & 2.38 \\
Home office \& Construction (34\% of TEP) & 1.05 \\
Contingency (15\% of TEP) & 0.28 \\
Legal expenses (4\% of TEP) & 1.33 \\
Contractors fee (19\% of TEP) & 7.28 \\
Total indirect capital costs (TIC) & 1.43 \\
Working capital (5\% of TDC+TIC) & 0.031 \\
Solvent cost & 30.1 \\
& \\
Total capital investment & [a] \\
Ta] This estimated capital investment is for synthesizing capric acid via microbial technology that has achieved \\
fermentation yields of $0.36 \mathrm{~g} \mathrm{~g}^{-1}$, volumetric productivity of $2 \mathrm{~g}^{-1} \mathrm{~h}^{-1}$, and fermentation titer of $75 \mathrm{~g}^{-1}$
\end{tabular}

Table 3

Operating expenses for capric acid production from glucose.

\begin{tabular}{lc}
\hline & Million U.S. Dollars 2015 \\
\hline & \\
Glucose & 10.7 \\
Media & 0.9 \\
Utilities & 1.7 \\
$n$-Hexane (make-up solvent) & $\approx 0$ \\
Waste disposal & 0.25 \\
Fixed costs $^{[\mathrm{a}]}$ & 2.9 \\
\hline
\end{tabular}

\footnotetext{
${ }^{[\mathrm{a}]}$ Fixed costs include labor wages, property taxes, insurance, operating overhead, and depreciation

These estimated operating expenses are for synthesizing capric acid via microbial technology that has achieved fermentation yields of $0.36 \mathrm{~g} \mathrm{~g}^{-1}$, volumetric productivity of $2 \mathrm{~g} \mathrm{l}^{-1} \mathrm{~h}^{-1}$, and fermentation titer of $75 \mathrm{~g} \mathrm{l}^{-1}$
} 


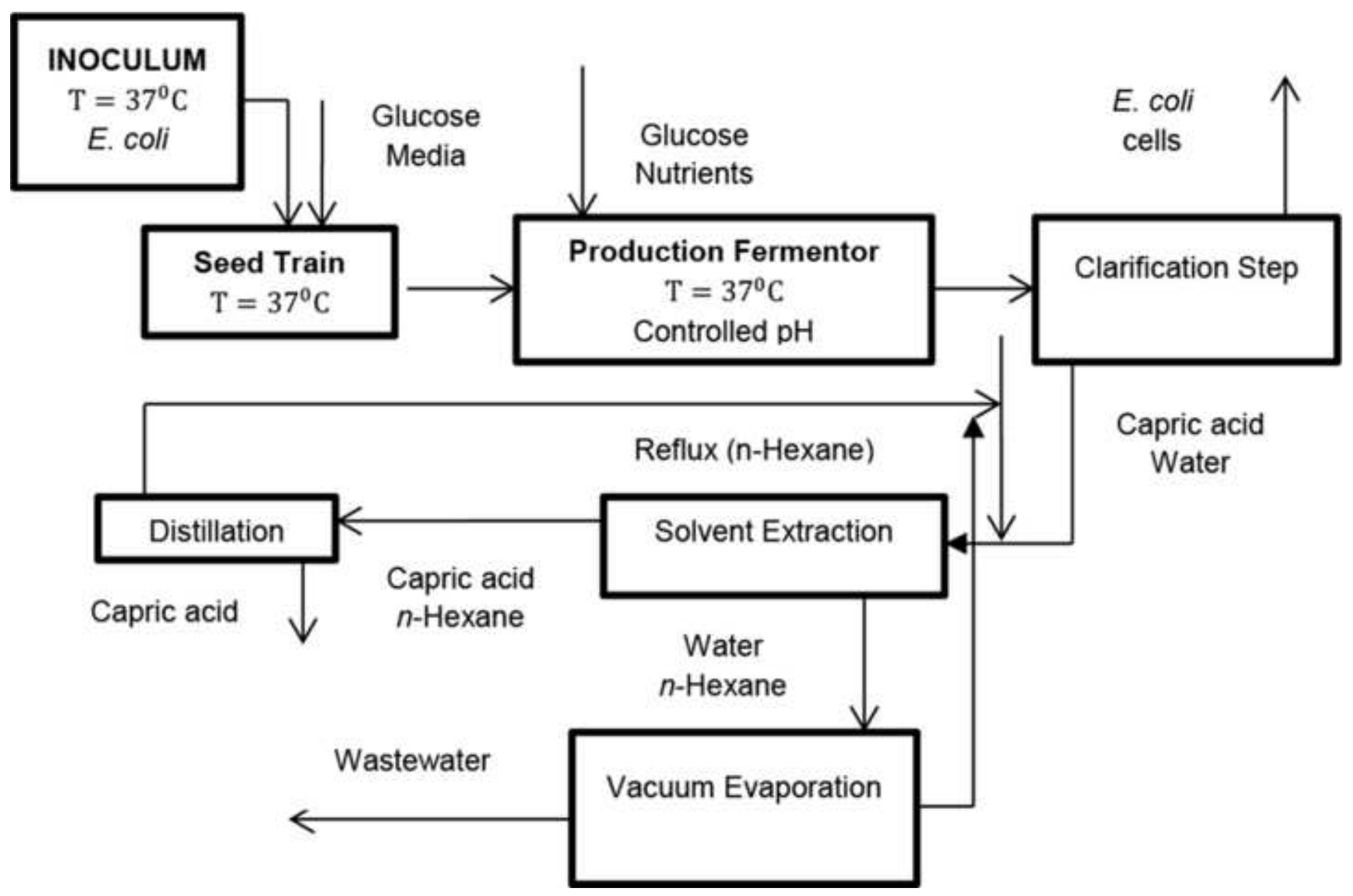


a
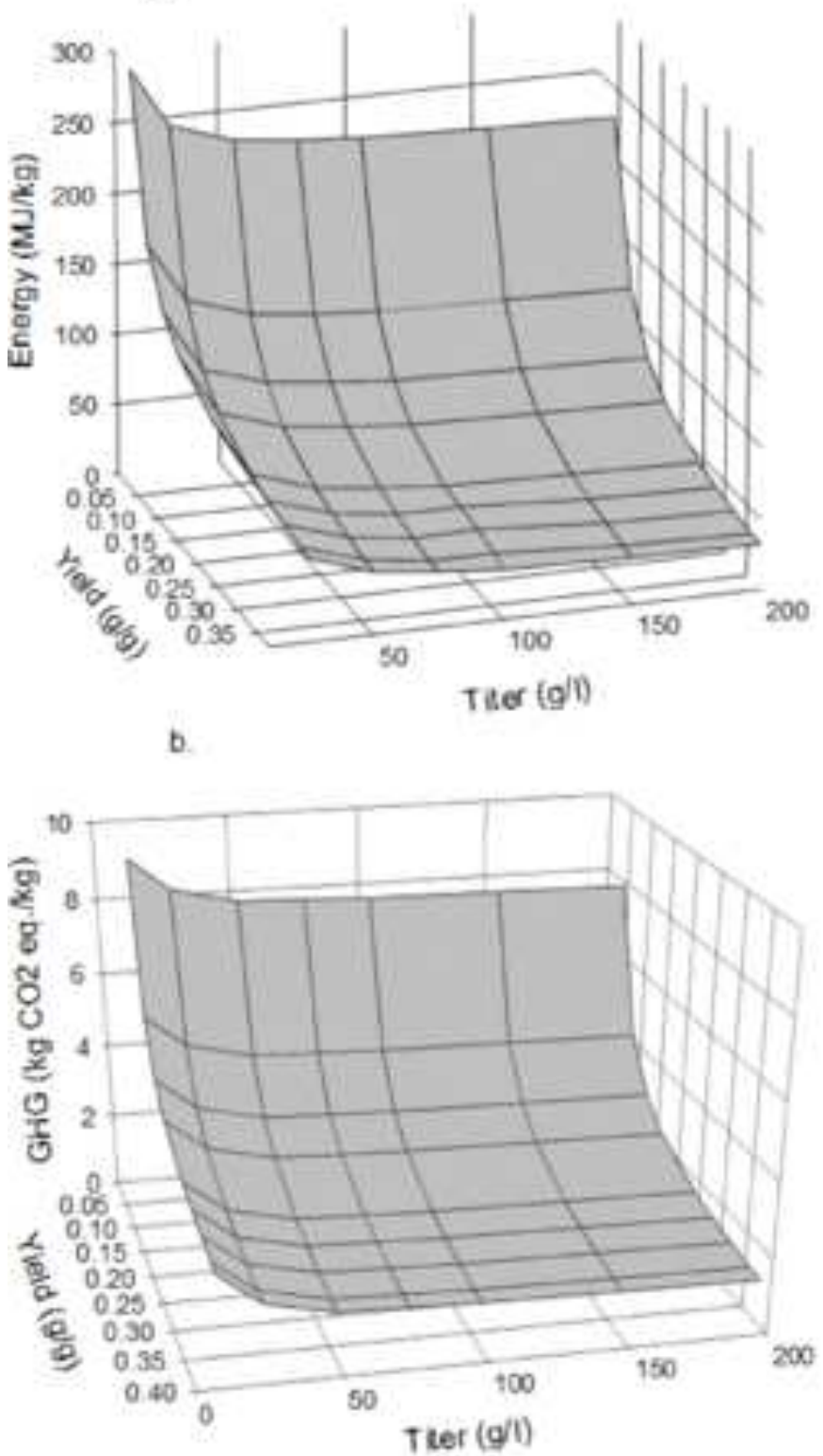

c.

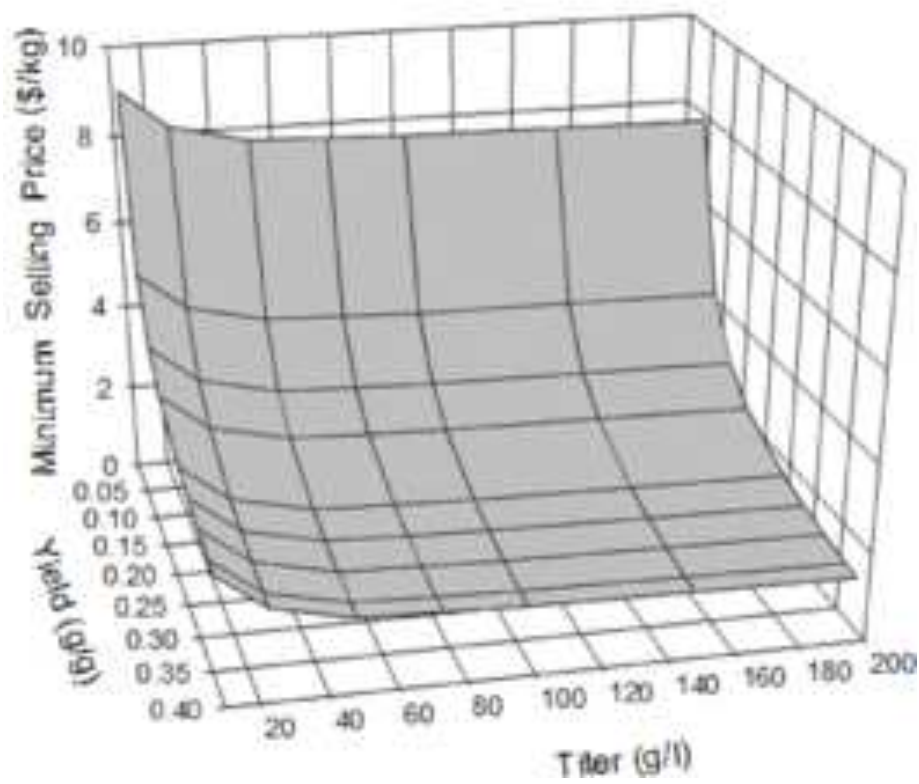



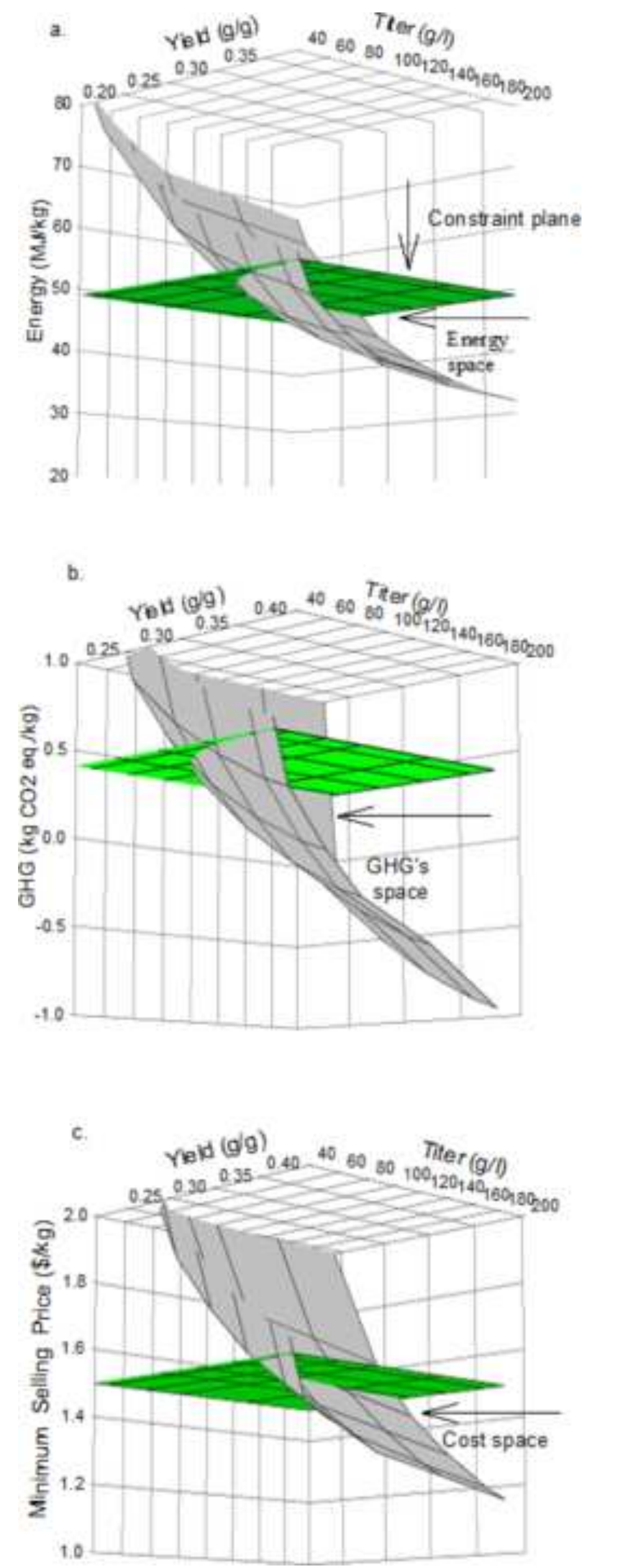

Figure 3

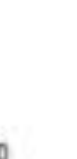
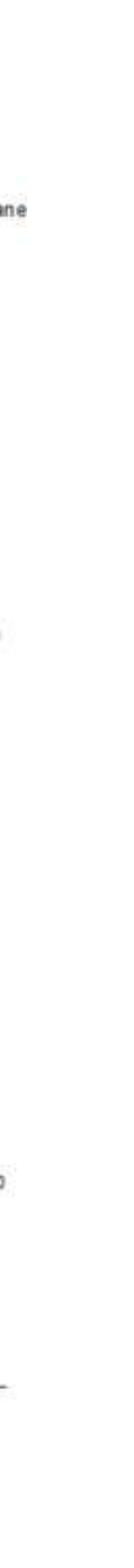

. 


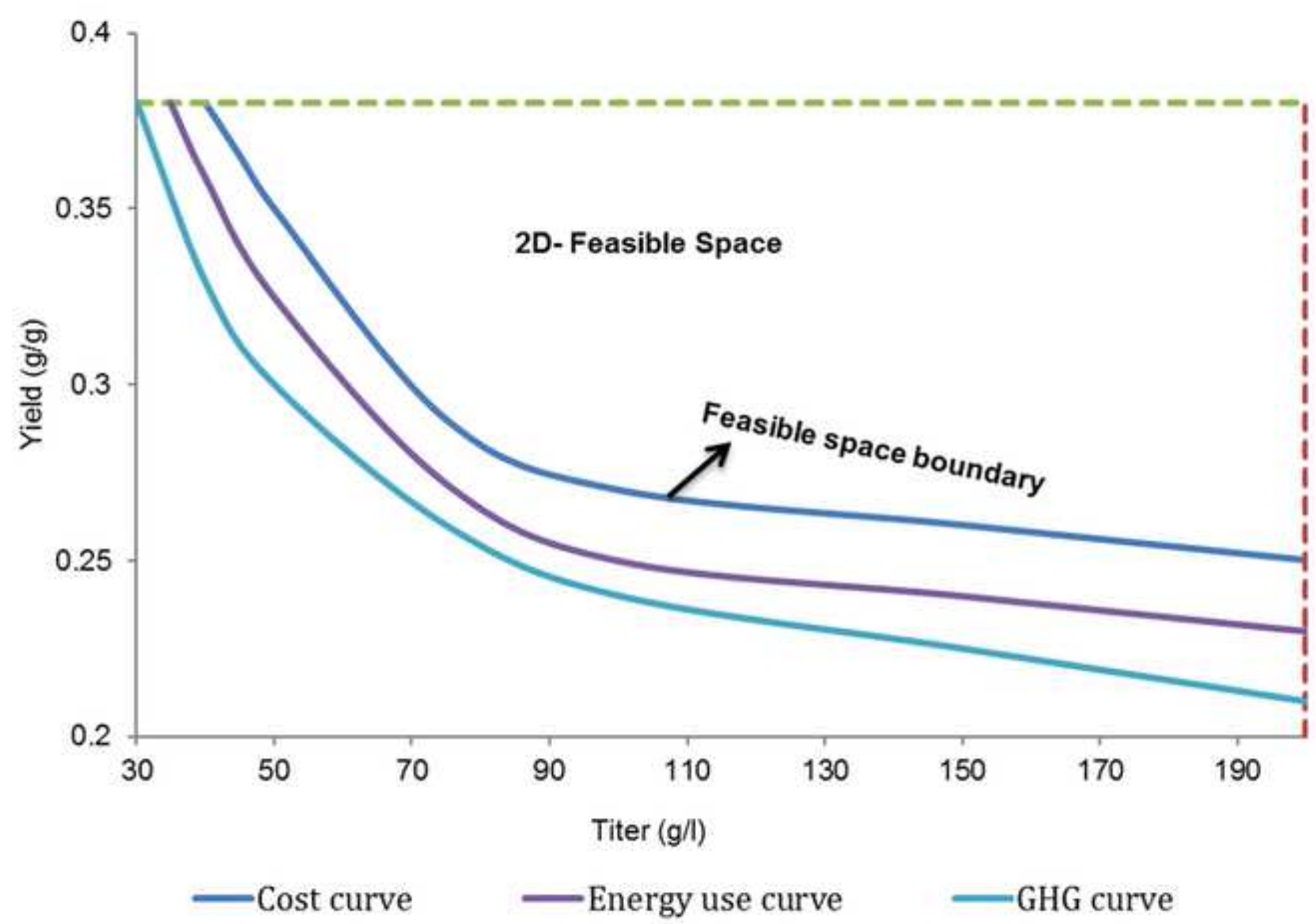

